\title{
INCIDÊNCIA DE NEVOEIRO NO AERÓDROMO DA ACADEMIA DA FORÇA AÉREA- PIRASSUNUNGA/SP - ANÁLISE DAS OCORRÊNCIAS
}

\author{
COLABONE, Rosângela de Oliveira - rosangelaroc@afa.aer.mil.br \\ Academia da Força Aérea/SP \\ VECCHIA, Francisco - fvecchia@sc.usp.br \\ CRHEA/EESC/USP - Univ. de São Paulo \\ FERRARI, Antonio Luiz - aferrari@sc.usp.br \\ CRHEA/EESC/USP - Univ. de São Paulo
}

\begin{abstract}
RESUMO. A distribuição de ocorrências de nevoeiro no aeródromo da Academia da Força Aérea-Pirassununga/SP- é investigada ao longo de uma série temporal de 20 anos (1989-2008). Foram aplicados aos dados climatológicos diários de superfície métodos estatísticos para identificação de anos habituais e excepcionais em termos de ocorrência do fenômeno e aplicação da proposta de Monteiro (1971) na classificação genética dos nevoeiros. O ano 2008, escolhido como o representante da categoria excepcional de alta incidência, foi analisado pela técnica da análise rítmica cujos resultados mostraram que no período de maior incidência do fenômeno - abril a julho - 83,3\% dos nevoeiros ocorreram sob a atuação da massa polar atlântica.

Palavras-chave: nevoeiro; análise de agrupamentos; análise rítmica; aeródromo da AFA.

FOG INCIDENCE IN AIRFIELD FORCE ACADEMY - PIRASSUNUNGA/SP - ANALYSIS OF EVENTS

ABSTRACT. The distribution of occurrences of fog on the airfield of Air Force Academy -Pirassununga/SP is investigated during 20 years (1989-2008) of data. Statistical methods were applied to the daily surface climatological data for classification of normal and exceptional year in terms of occurrence of the phenomenon and in order to apply Monteiro's proposal (1971) in the genetic classification of fog. The year of 2008, representing the category of exceptional high incidence, was analyzed by the method of rhythm analysis whose results showed that the period of highest incidence of the phenomenon (april-june) $83,3 \%$ of fog occurred under the action of atlantic polar mass.

Key-words: fog; unusual occurrences; cluster analysis; rhythm analysis; aerodrome AFA.
\end{abstract}

\section{INTRODUÇÃO}

Segundo concepção internacional, nevoeiro consiste de uma grande quantidade de gotículas de água em suspensão ou cristais de gelo perto da superfície da Terra e que leva a uma redução da visibilidade horizontal abaixo de $1 \mathrm{~km}$ (NATIONAL OCEANIC AND ATMOSPHERIC ADMINISTRATION, 1995). Para o Departamento de Controle do Espaço Aéreo - DECEA (2008), quando a visibilidade predominante for reduzida por gotículas d'água ou cristais de gelo para menos de 1.000 metros caracteriza-se a formação de nevoeiro.

A presença de gotículas suspensas e/ou cristais de gelo gera condições de baixa visibilidade, podendo deixar indistinguível um objeto para um observador distante. Dessa maneira o fenômeno meteorológico perigoso causa impacto nos meios de transporte rodoviário, marítimo e aéreo (GULTEPE et al., 2007). Para o setor aeronáutico, a ocorrência de nevoeiro em aeroportos pode acarretar atrasos e até mesmo cancelamentos de voos, com perdas financeiras substanciais para o setor da aviação, devido a modificações nos planejamentos de voos das empresas, despesas extras com hotéis e combustível, demasiada ocupação dos pátios dos aeroportos alternativos e consequentemente sobrecarga operacional nos sistemas desses aeroportos, sem se levar em conta os prejuízos aos passageiros (OLIVEIRA, 2002).

$\mathrm{Na}$ Academia da Força Aérea (AFA), local onde são formados os futuros oficiais da Força Aérea Brasileira, o fenômeno também ocorre e afeta diretamente as atividades de instrução de voo, comprometendo o planejamento anual e acarretando problemas ao calendário escolar.

A AFA (21059'07" S, 47020'06" O, altitude $600 \mathrm{~m}$ ) está localizada no município de Pirassununga/SP, ocupando uma área de $65.027 .015 \mathrm{m2}$, com um aeródromo para o desenvolvimento das atividades de voo do seu Curso de Formação de Oficiais Aviadores. Todas as atividades de ensino ali desenvolvidas, inclusive as relacionadas à instrução aérea, seguem um planejamento anual, embora, no caso das atividades aéreas, o planejamento seja bastante prejudicado pela incidência de nevoeiros, que provocam atrasos e cancelamentos dos voos de instrução.

Este trabalho apresenta os resultados das análises efetuadas para estudo da distribuição das ocorrências de nevoeiro durante 20 anos no aeródromo da Academia da Força Aérea. Foram 
aplicados métodos estatísticos de classificação para agrupamento dos anos nas categorias habitual e excepcional (alta e baixa incidência) em relação à ocorrência do fenômeno. Ao ano escolhido como excepcional de alta ocorrência foi aplicado o método de análise rítmica (Monteiro, 1971) para identificação dos sistemas atmosféricos que atuaram na região e participaram da gênese dos nevoeiros.

A análise rítmica é uma maneira de investigar a realidade climática de cada lugar, considerando-se os atributos fundamentais do clima em unidades de tempo cronológicas diárias, compatíveis com a representação da circulação atmosférica regional (TAVARES, 1976). Para solucionar o problema de analise de séries muito longas, Monteiro (1971) no estudo da dinâmica atmosférica e das chuvas no Estado de São Paulo, utilizou os anos-padrão para a realização da análise rítmica.

Para determinação dos anos-padrão são utilizados métodos de classificação de dados, entre os quais o de "análise hierárquica por pares recíprocos" ou análise de agrupamento como aplicou Boin (2000) numa série temporal de 30 anos para o estudo do impacto provocado pelas chuvas no Oeste Paulista. Zandonadi (2009), ao estudar a distribuição temporal e espacial das chuvas na bacia do Paraná, aplicou a técnica de Sturges para selecionar os anos-padrão dentro do período de 1976 a 2005.

\section{MATERIAIS E MÉTODOS}

Os dados meteorológicos da série temporal de 20 anos (1989-2008) foram fornecidos pelo Instituto de Controle do Espaço Aéreo - ICEA de São José dos Campos/SP, órgão responsável pelo banco de dados meteorológicos da Aeronáutica. Todas as medições foram realizadas das 5 às 23 horas, horários em que são iniciadas e finalizadas, respectivamente, as atividades do aeródromo da AFA.

Para se conhecer a distribuição dos nevoeiros ao longo dos 20 anos estudados, fez-se uma análise de intervalos de classe definidos, a partir dos dados de incidência de nevoeiro. Para isso, aplicou-se a técnica estatística de classificação que utiliza como suporte a fórmula de Sturges (GERARDI; SILVA, 1981; RAMOS; SANCHES, 2000):

$$
k=1+3,33 \log N
$$

onde, $\mathrm{k}$ corresponde ao número de classes e $\mathrm{N}$ corresponde ao número total de elementos da série.

O intervalo de cada classe foi obtido pela divisão da amplitude dos dados pelo número de classes definido pela fórmula de Sturges.

Além do número de classes definidas pela fórmula de Sturges, atribuiu-se uma classe adicional para representar a ausência de nevoeiro. Para a distribuição da ocorrência de nevoeiro ao longo do período estudado associou-se a cada classe uma cor, construindo-se uma planilha cromática com a classificação mensal de ocorrência de nevoeiro. As cores utilizadas para cada classe variaram do verde claro (baixa incidência de nevoeiro) ao azul profundo (alta incidência de nevoeiro). Para os meses em que não houve ocorrência do fenômeno, não se atribuiu cor, visto que o foco deste estudo é a incidência do fenômeno e não a sua ausência. A representação cromática dos intervalos de classe é um procedimento utilizado na classificação dos valores habituais de chuva, como fez Zandonadi (2009).

Uma vez analisada a distribuição dos nevoeiros ao longo dos anos estudados e identificado o período de maior ocorrência do fenômeno, procurou-se, então, agrupar os anos com características similares e destacar aqueles que apresentam padrão de ocorrências diferente do esperado, classificando-os em anos habituais e excepcionais (alta e baixa ocorrência). Entende-se por ocorrência o número de dias em que o fenômeno se manifesta sem consideração da duração do mesmo. 
A similaridade pode ser associada à proximidade ou vizinhança ou, ainda, à distância que separa dois elementos nesse espaço. Assim, dois períodos colocados vizinhos no espaço relativo-estatístico podem situar-se distantes no espaço absoluto e a similaridade, mensurada de várias maneiras: por correlação, diferença numérica simples, diferenças múltiplas agregadas.

Existem algumas formas de apresentar os dados em certas medidas de distância e algumas regras ou algoritmos para agrupar objetos que podem ser itens ou variáveis. Buscar uma estrutura de agrupamento natural formando grupos homogêneos segundo as características dos dados é uma importante técnica exploratória.

Para esse procedimento aplicou-se aos dados anuais da série temporal a técnica da "análise hierárquica por pares recíprocos", também conhecida como Método de McQuitty (MCQUITTY, 1966; DINIZ, 1971; SANCHEZ, 1972), onde as distâncias entre os elementos dos grupos são definidas por:

$$
d_{(K L) J}=\frac{\left(d_{K L}+d_{L J}\right)}{2}
$$

Onde:

- $d_{(K L)} \mathrm{J}$ é a distância entre o agrupamento $(K L)$ e o agrupamento J;

- $d_{K L}$ e $d_{L J}$ são as distâncias entre a maior distância dos membros dos agrupamentos $\mathrm{K}$ e J e dos agrupamentos L e J. O programa SAS, versão 8.2, foi utilizado para obtenção dos agrupamentos que são apresentados em forma de dendrograma.

Após a separação dos grupos foi escolhido um ano representativo da categoria excepcional de alta incidência para aplicação da técnica de análise rítmica com objetivo de se definir o caráter genético dos nevoeiros no aeródromo da AFA.

\section{DISCUSSÃO DOS RESULTADOS}

\section{Climatologia de nevoeiro para o aeródromo da AFA}

O gráfico 1 mostra a frequência relativa e a frequência absoluta das ocorrências de nevoeiro observadas no aeródromo da AFA no período de 1989 a 2008: de um total de 821 casos de nevoeiros, $67 \%$ das ocorrências aconteceram nos meses de abril a julho, com predominância nos meses de maio e junho. As menores frequências ocorreram nos meses outubro, novembro, dezembro e janeiro, com um total de $9,5 \%$, e, nos meses fevereiro, março, agosto e setembro a incidência ficou em torno de $23,4 \%$.

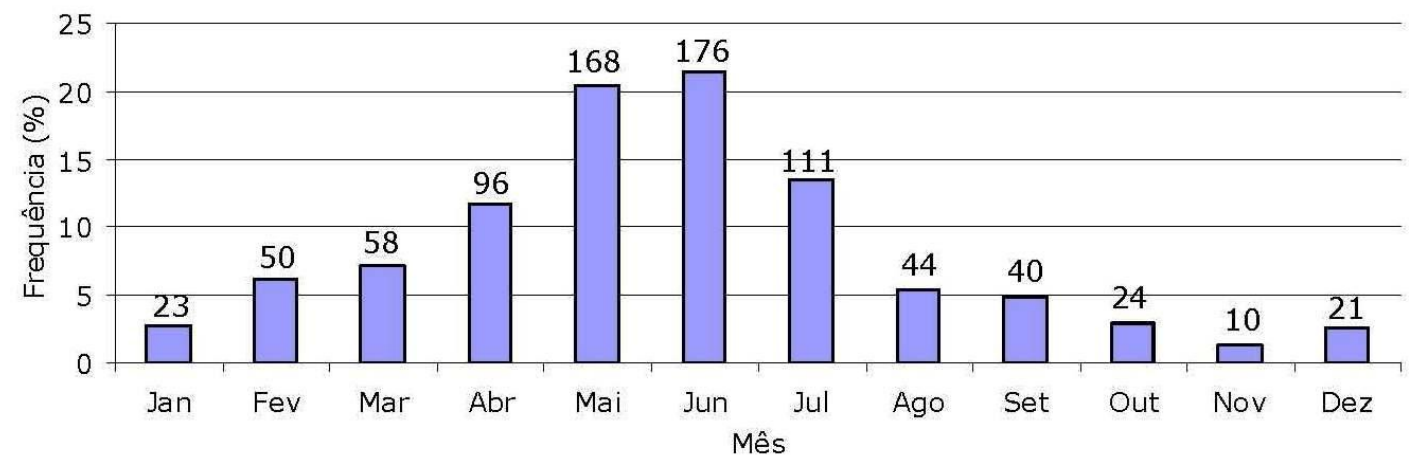

Gráfico 1. Frequência relativa e frequência absoluta (números acima das colunas) de ocorrência de nevoeiro no aeródromo da AFA no período 1989-2008.

O gráfico 2 apresenta o total anual de horas com nevoeiro para os 20 anos considerados. A análise desse gráfico destaca o ano de 1998 (127 h) como de maior número de horas de nevoeiro e 2000 ( 36 h), como o de menor número de horas. 


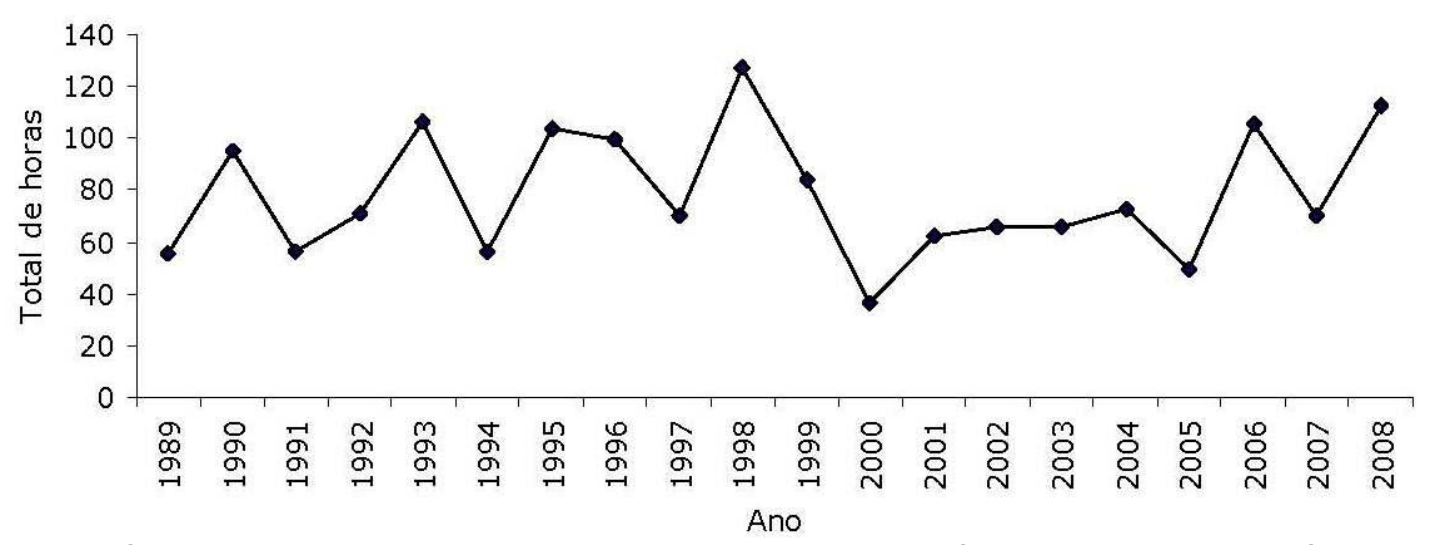

Gráfico 2. Total anual de horas de nevoeiros para o aeródromo da AFA no período 1989 a 2008.

O gráfico 3 apresenta o total mensal de horas com nevoeiro para o período 1989-2008: os meses de maior ocorrência de horas de nevoeiro são abril (166 h), maio (333 h), junho (382 h) e julho (240 h). Os meses de menor ocorrência de horas de nevoeiro são outubro (34 h), novembro (17 h), dezembro (29 h) e janeiro (35 h).

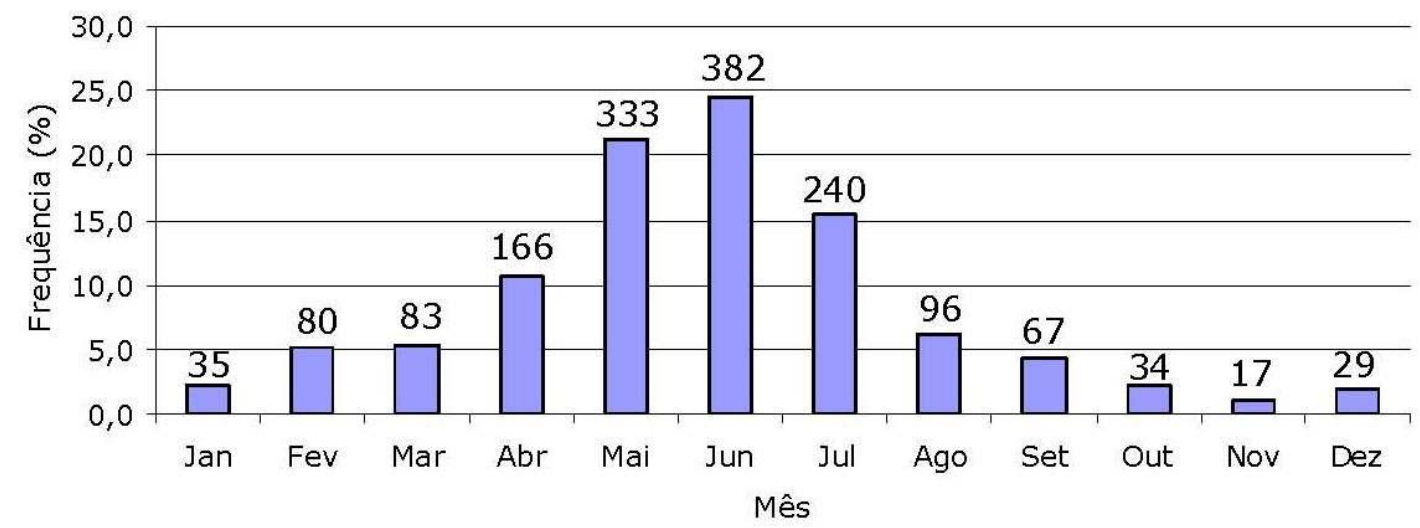

Gráfico 3. Frequência relativa (\%) e frequência absoluta (números acima das colunas) de totais mensais de horas com nevoeiro no aeródromo da AFA no período 1989-2008.

O gráfico 4 mostra o total de horas discriminado para os meses de maior incidência (abril, maio, junho e julho): o ano 1998 teve o maior número de horas de nevoeiro ( $89 \mathrm{~h}$ ), seguido do ano 2008, com 79 h. O ano 2000 teve o menor número de horas (15 h), seguido do ano 2005, com $37 \mathrm{~h}$ para o mesmo período. Destaca-se também junho de 1999 como o de maior número de horas de nevoeiro (39 h).

\section{口abril $\square$ maio $\square$ junho $\square$ julho}

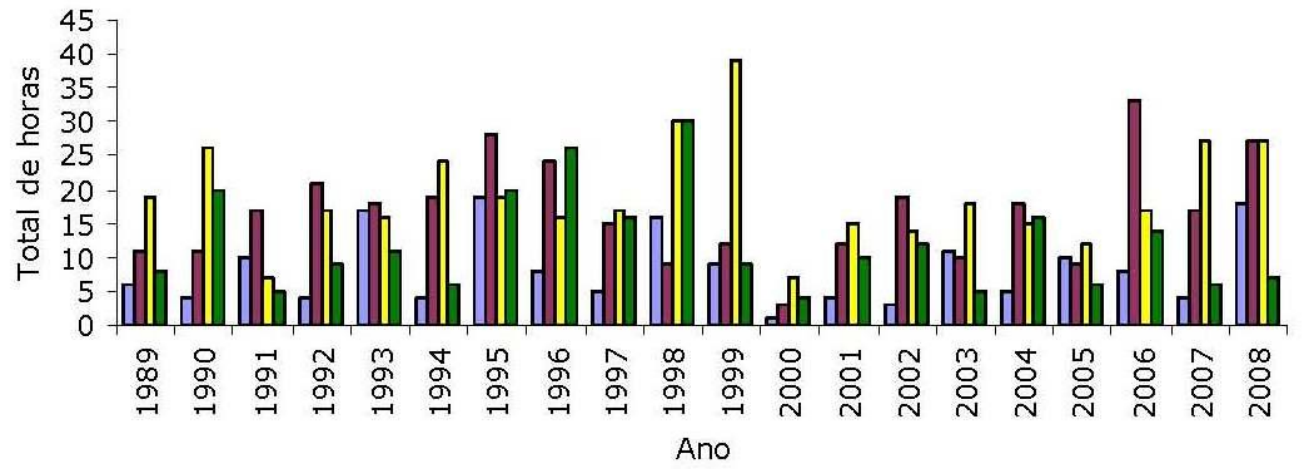


Gráfico 4. Totais de horas anuais de nevoeiros para os meses abril, maio, junho e julho para o aeródromo da AFA.

\section{Planilha cromática de ocorrência mensal de nevoeiro para o período 1989-2008}

Para os dados do período de 20 anos, a aplicação da fórmula de Sturges resultou em 9 classes com os intervalos de classe apresentados no Quadro 1. Para cada classe definida associou-se uma cor, sendo reservada a ausência de cor para a classe que representa a ausência do fenômeno.

Quadro 1

Intervalos de classes e a escala cromática associada.

\begin{tabular}{|c|c|c|c|}
\hline Classes & Limite mínimo & Limite máximo & Cor associada \\
\hline Ausência de nevoeiro & 0 & 0 & \\
\hline $1 .^{a}$ classe & 0,12 & 0,31 & \\
\hline 2. a classe & 0,32 & 0,51 & \\
\hline 3. a classe & 0,52 & 0,71 & \\
\hline 4. ${ }^{a}$ classe & 0,72 & 0,91 & \\
\hline 5. a classe & 0,92 & 1,11 & \\
\hline 6. a classe & 1,12 & 1,31 & \\
\hline 7. a classe & 1,32 & 1,51 & \\
\hline 8. a classe & 1,52 & 1,71 & \\
\hline 9. ${ }^{a}$ classe & 1,72 & 1,91 & \\
\hline
\end{tabular}

Com os intervalos de classe assim definidos, construiu-se uma planilha cromática com a escala de cor associada para melhor visualização da distribuição de ocorrências de nevoeiro no período de 20 anos (Quadro 2).

\section{Quadro 2}

\section{Planilha cromática associada às frequências absolutas de ocorrência mensal de} nevoeiro para o período 1989-2008.

\begin{tabular}{|l|l|l|l|l|l|l|l|l|l|l|l|l|}
\hline Ano & JAN & FEV & MAR & ABR & MAI & JUN & JUL & AGO & SET & OUT & NOV & DEZ \\
\hline $\mathbf{1 9 8 9}$ & 0,12 & 0,24 & 0,37 & 0,37 & 1,46 & 1,46 & 0,73 & 0,37 & 0,12 & 0,12 & 0,12 & 0,00 \\
\hline $\mathbf{1 9 9 0}$ & 0,12 & 0,12 & 0,73 & 0,37 & 0,73 & 1,22 & 0,85 & 0,37 & 0,61 & 0,12 & 0,00 & 0,12 \\
\hline $\mathbf{1 9 9 1}$ & 0,00 & 0,49 & 0,12 & 0,73 & 1,34 & 0,73 & 0,37 & 0,12 & 0,00 & 0,12 & 0,00 & 0,37 \\
\hline $\mathbf{1 9 9 2}$ & 0,12 & 0,12 & 0,73 & 0,37 & 0,97 & 0,73 & 0,61 & 0,12 & 0,49 & 0,12 & 0,12 & 0,12 \\
\hline $\mathbf{1 9 9 3}$ & 0,12 & 0,61 & 0,61 & 1,10 & 0,85 & 0,73 & 0,73 & 0,61 & 0,49 & 0,12 & 0,00 & 0,00 \\
\hline $\mathbf{1 9 9 4}$ & 0,00 & 0,00 & 0,00 & 0,61 & 1,34 & 1,34 & 0,37 & 0,12 & 0,00 & 0,00 & 0,12 & 0,12 \\
\hline $\mathbf{1 9 9 5}$ & 0,00 & 0,49 & 0,24 & 1,34 & 1,34 & 1,10 & 0,73 & 0,00 & 0,00 & 0,49 & 0,00 & 0,12 \\
\hline $\mathbf{1 9 9 6}$ & 0,12 & 0,24 & 0,24 & 0,61 & 1,10 & 0,61 & 0,97 & 0,12 & 0,49 & 0,24 & 0,00 & 0,24 \\
\hline $\mathbf{1 9 9 7}$ & 0,12 & 0,24 & 0,24 & 0,24 & 0,85 & 0,97 & 0,85 & 0,12 & 0,12 & 0,12 & 0,00 & 0,24 \\
\hline $\mathbf{1 9 9 8}$ & 0,12 & 0,85 & 0,49 & 0,97 & 0,73 & 1,34 & 1,46 & 0,73 & 0,12 & 0,24 & 0,12 & 0,12 \\
\hline $\mathbf{1 9 9 9}$ & 0,24 & 0,00 & 0,37 & 0,49 & 0,97 & 1,83 & 0,61 & 0,00 & 0,49 & 0,00 & 0,00 & 0,12 \\
\hline $\mathbf{2 0 0 0}$ & 0,37 & 0,00 & 0,24 & 0,12 & 0,37 & 0,49 & 0,37 & 0,37 & 0,24 & 0,24 & 0,12 & 0,24 \\
\hline $\mathbf{2 0 0 1}$ & 0,37 & 0,24 & 0,49 & 0,37 & 0,85 & 0,97 & 0,73 & 0,12 & 0,00 & 0,12 & 0,24 & 0,12 \\
\hline $\mathbf{2 0 0 2}$ & 0,12 & 0,24 & 0,37 & 0,37 & 1,10 & 0,85 & 0,85 & 0,37 & 0,12 & 0,00 & 0,00 & 0,12 \\
\hline $\mathbf{2 0 0 3}$ & 0,12 & 0,24 & 0,12 & 0,73 & 0,73 & 1,22 & 0,49 & 0,49 & 0,24 & 0,00 & 0,00 & 0,00 \\
\hline $\mathbf{2 0 0 4}$ & 0,00 & 0,49 & 0,24 & 0,24 & 0,97 & 0,73 & 0,85 & 0,37 & 0,12 & 0,24 & 0,12 & 0,00 \\
\hline $\mathbf{2 0 0 5}$ & 0,24 & 0,12 & 0,12 & 0,61 & 0,73 & 0,73 & 0,37 & 0,00 & 0,37 & 0,12 & 0,00 & 0,00 \\
\hline $\mathbf{2 0 0 6}$ & 0,12 & 0,37 & 0,37 & 0,61 & 1,71 & 1,22 & 0,73 & 0,49 & 0,24 & 0,37 & 0,12 & 0,12 \\
\hline $\mathbf{2 0 0 7}$ & 0,37 & 0,12 & 0,37 & 0,37 & 0,85 & 1,58 & 0,49 & 0,00 & 0,00 & 0,12 & 0,00 & 0,12 \\
\hline $\mathbf{2 0 0 8}$ & 0,00 & 0,85 & 0,61 & 1,10 & 1,46 & 1,58 & 0,37 & 0,49 & 0,61 & 0,00 & 0,12 & 0,24 \\
\hline
\end{tabular}

Os intervalos de classes permitiram, por meio da escala de cor associada, confirmar que os meses de maior incidência de nevoeiro no aeródromo da AFA são abril, maio, junho e julho, 
constituindo-se, dessa maneira, o "período habitual" para o aparecimento do fenômeno. Podem-se destacar dois outros períodos: o que compreende os meses de outubro a janeiro e aquele com os meses fevereiro, março, agosto e setembro, representantes de períodos com baixa e média ocorrência de nevoeiro, respectivamente.

A análise do Quadro 2 mostra que, nos anos de 1993 e 2008, a incidência significativa de nevoeiro começou logo em fevereiro e se estendeu até setembro, indicando distribuição do fenômeno em meses diferentes em relação à maioria dos anos analisados. Já em 1998 a incidência do fenômeno se estendeu de fevereiro a agosto, aparecendo aqui o mês de julho com uma contribuição mais significativa. O ano 2000 destaca-se, também, pela distribuição não habitual das ocorrências de nevoeiro. No período considerado "habitual" de incidência, as ocorrências não foram muito significativas, reunindo-se na mesma classe os meses de janeiro, maio, julho e agosto. Além disso, a distribuição de classes desse ano não é compatível com a habitual, podendo, portanto, ser considerado excepcional, com baixa incidência do nevoeiro.

O Gráfico 5 mostra o histograma das ocorrências de nevoeiro no período habitual (abril a julho) para os 20 anos analisados.

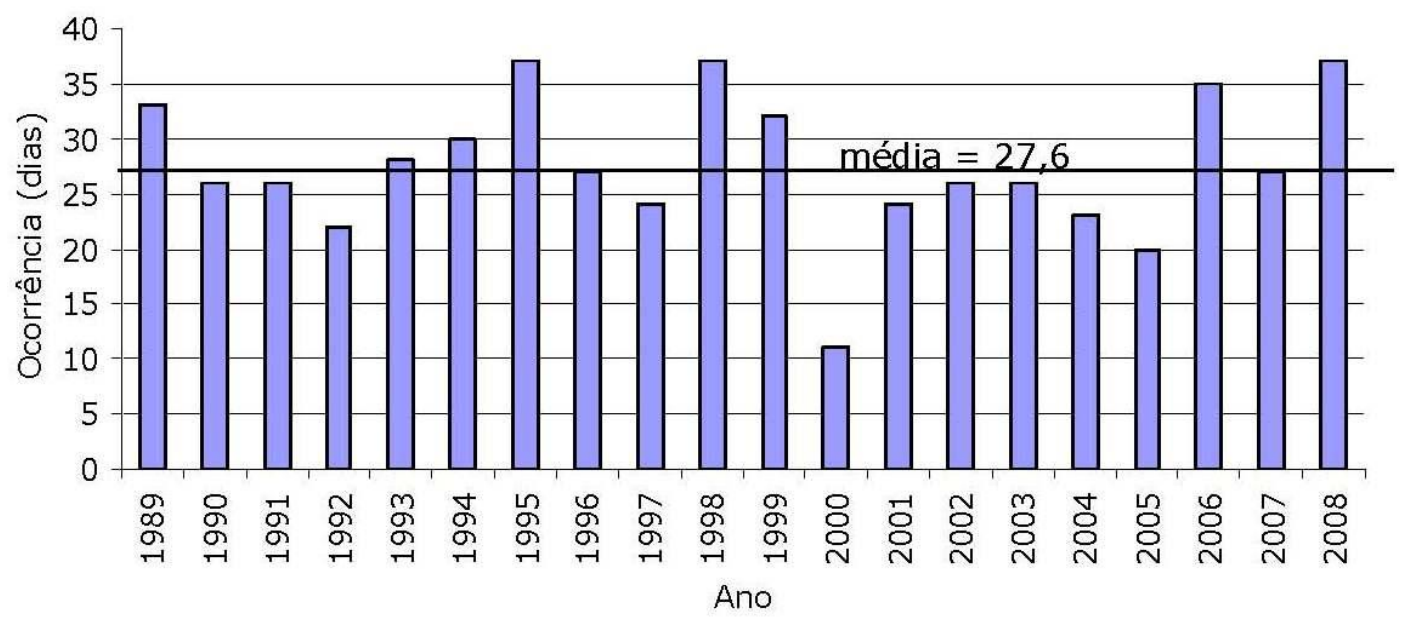

Gráfico 5. Histograma das ocorrências de nevoeiro no período habitual (abril, maio, junho e julho) para a série temporal.

A média de ocorrências para o período de maior incidência ficou em torno de 27,6 dias. Verifica-se que sete anos (1989, 1993, 1994, 1995, 1998, 1999, 2006 e 2008) tiveram ocorrências acima da média e somente o ano 2000 se destacou, mais uma vez, pelo menor número de ocorrências.

\section{Classificação dos anos em termos de ocorrência}

A figura 1 apresenta o resultado da aplicação da técnica de "análise hierárquica por pares recíprocos" aos dados da série temporal. Assim buscou-se agrupar os anos em três categorias representativas dos comportamentos habitual, excepcional de alta ocorrência e excepcional de baixa ocorrência. Após análise do dendrograma foram definidos os seguintes grupos:

- Grupo 1 - alta ocorrência de nevoeiro, formado pelos anos 1993, 1995, 2006, 1998 e 2008. Apresenta, em relação aos outros dois grupos, maiores frequências de ocorrência de nevoeiro;

- Grupo 2 - baixa ocorrência de nevoeiro, constituído pelos anos 2000 e 2005, que apresentam os menores valores de frequência;

- Grupo 3 - habitual, formado pelos anos 1989, 1990, 1991, 1992, 1993, 1994, 1996, 1997, 2001, 2002, 2003, 2004 e 2007. 


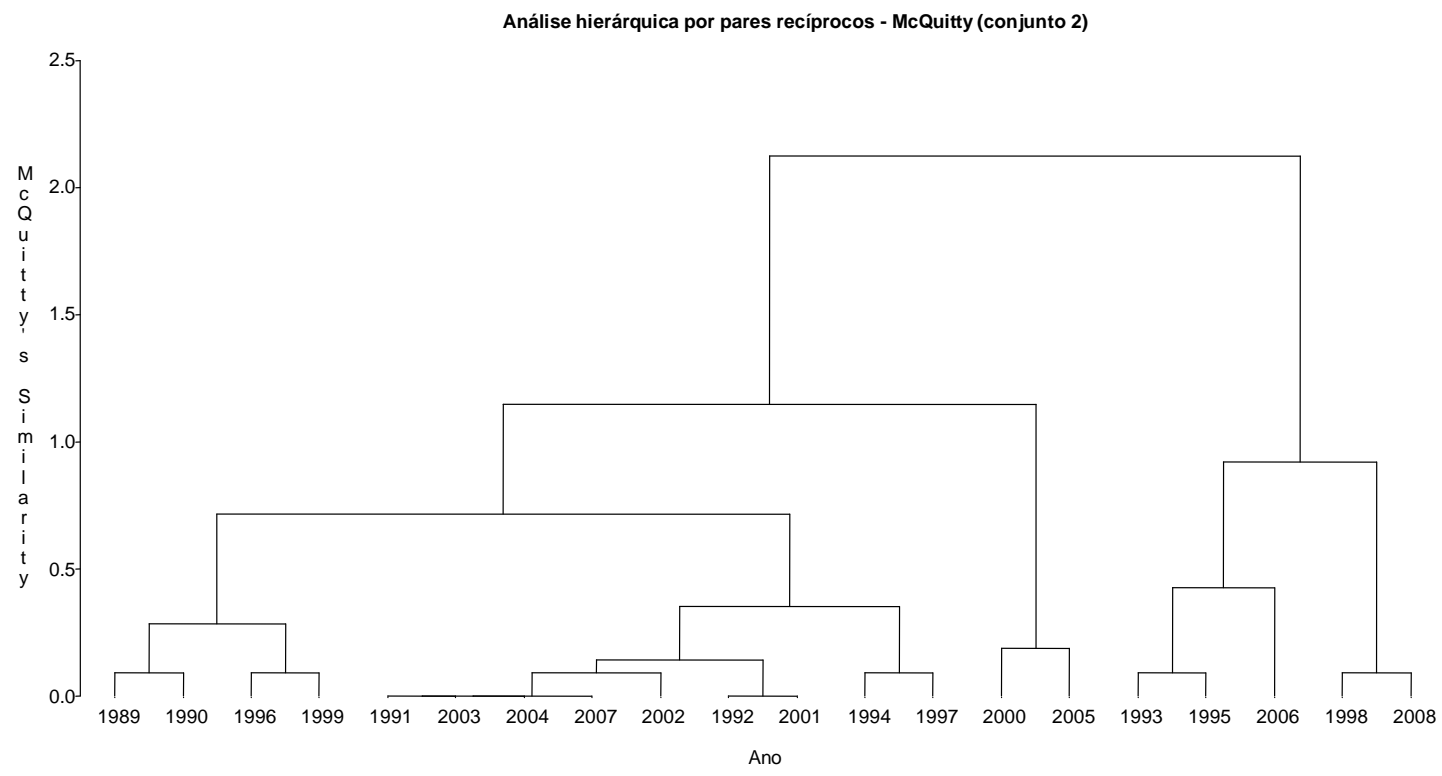

Figura 1. Dendrograma anual das ocorrências de nevoeiro no aeródromo da AFA no período 1989 a 2008.

\section{Análise do ano 2008 - excepcional de alta incidência}

O ano 2008 foi escolhido como representante da categoria excepcional de alta incidência. A aplicação da técnica de análise rítmica proposta por Monteiro (1971) permitiu identificar os sistemas atmosféricos atuantes no período de maior incidência de nevoeiro (abril a julho) no aeródromo da AFA. A Tabela 1 fornece a frequência de participação de cada sistema atmosférico no período analisado.

Observa-se que, de uma maneira geral, a massa polar atlântica, geradora de tempos estáveis com temperaturas baixas, atuou $57,5 \%$, seguida da massa polar velha $(11,5 \%)$, que também promove tempos estáveis, mas com aumento de nebulosidade e da temperatura mínima. A frente polar atlântica atuou em $8,2 \%$ do total, gerando precipitação pluviométrica, em conformidade com comportamento verificado por MONTEIRO (1971). As linhas de instabilidades, tanto em massa polar como em massa tropical, que provocam aumento na nebulosidade, e, às vezes, baixos valores pluviométricos, estiveram presentes em $5,8 \%$ do período analisado.

A Tabela 2 resume os sistemas atmosféricos atuantes nos episódios de nevoeiro dos meses abril a julho. Verifica-se que somente no mês de abril os nevoeiros ocorreram sob o domínio de três sistemas atmosféricos diferentes: massa polar atlântica $(37,5 \%)$, massa polar velha $(25 \%)$ e frente polar reflexa (35\%). Nos outros meses os nevoeiros ocorreram exclusivamente sob a atuação da massa polar atlântica.

A Figura 2 ilustra a participação dos sistemas atmosféricos nos episódios de nevoeiro para todo período analisado. É evidente a participação da massa polar atlântica na gênese do fenômeno $(83,3 \%)$. A massa polar velha também atuou, embora em menor proporção (5,5\%), nos dias de ocorrência do nevoeiro. O domínio da massa polar atlântica favorece condições de tempo onde há rápido declínio das temperaturas e, consequentemente, maiores amplitudes térmicas, céu claro, sem nuvens, o que favorece o transporte radioativo de calor durante a noite.

Outra condição sinótica observada no local estudado relacionou-se à frente polar reflexa. Quando esse sistema atua no litoral de São Paulo e Rio de Janeiro, ocorre aumento na nebulosidade e, consequentemente, aumento na umidade relativa do ar, sem geração de precipitação. Nessas condições houve também a formação de nevoeiro $(11,1 \%)$. 
Tabela 1

Frequência de participação dos sistemas atmosféricos no período de abril a julho de 2008 no aeródromo da AFA

\begin{tabular}{ccccc}
\hline $\begin{array}{c}\text { Sistemas } \\
\text { atmosféricos }\end{array}$ & $\begin{array}{c}\text { Abril } \\
(\%)\end{array}$ & $\begin{array}{c}\text { Maio } \\
(\%)\end{array}$ & $\begin{array}{c}\text { Junho } \\
(\%)\end{array}$ & $\begin{array}{c}\text { Julho } \\
(\%)\end{array}$ \\
\hline mTa & 0,0 & 0,0 & 0,8 & 0,8 \\
mTa com LI & 1,6 & 0,0 & 0,8 & 0,0 \\
mPa & 5,7 & 18,9 & 14,8 & 18,0 \\
mPa com LI & 1,6 & 4,1 & 2,5 & 0,0 \\
mPv com LI & 3,3 & 0,0 & 0,0 & 0,0 \\
mPv & 3,3 & 1,6 & 2,5 & 4,1 \\
FPA & 4,1 & 0,8 & 0,8 & 2,5 \\
FPAE & 1,6 & 0,0 & 0,0 & 0,0 \\
RFPA & 0,0 & 0,0 & 0,8 & 0,0 \\
FPR & 3,3 & 0,0 & 1,64 & 0,0 \\
\hline
\end{tabular}

$\mathrm{mPa}$ - massa polar atlântica

mTa - massa tropical atlântica

$\mathrm{mPv}$ - massa polar velha

mPa com LI - massa polar atlântica com linhas de instabilidades

$\mathrm{mPv}$ com LI - massa polar velha com linhas de instabilidades

mTa com Li - massa tropical atlântica com linhas de instabilidade

FPA - frente polar atlântica

FPR - frente polar reflexa

RFPA - repercussão da frente polar atlântica

Tabela 2

Identificação dos sistemas atmosféricos atuantes nos episódios de nevoeiro no aeródromo da AFA nos meses abril a julho de 2008.

\begin{tabular}{lcccc}
\hline $\begin{array}{c}\text { Sistemas } \\
\text { atmosféricos }\end{array}$ & $\begin{array}{c}\text { Abril } \\
(\%)\end{array}$ & $\begin{array}{c}\text { Maio } \\
(\%)\end{array}$ & $\begin{array}{c}\text { Junho } \\
(\%)\end{array}$ & $\begin{array}{c}\text { Julho } \\
(\%)\end{array}$ \\
\hline MPA & 37,5 & 100 & 92,3 & 100 \\
MPV & 25,0 & 0 & 0 & 0 \\
FPR & 37,5 & 0 & 7,7 & 0 \\
\hline
\end{tabular}

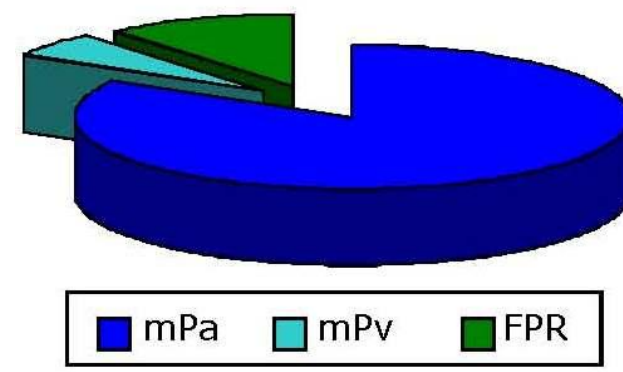

Figura 2. Sistemas atmosféricos atuantes nos episódios de nevoeiros no aeródromo para todo período analisado. 


\section{CONSIDERAÇÕES FINAIS}

Este estudo permitiu verificar a distribuição das ocorrências de nevoeiro no aeródromo da Academia da Força Aérea ao longo de uma série temporal de 20 anos, evidenciando-se o período de abril a julho como o de maior incidência do fenômeno.

Por meio de técnicas de classificação foi possível escolher um ano representativo da categoria excepcional de alta ocorrência para aplicação do método de análise rítmica no período em que fenômeno mais ocorre.

Ficou evidente que, no período de abril a julho do ano 2008, houve predominância da massa polar atlântica na gênese dos episódios de nevoeiros no aeródromo da AFA, sendo que alguns deles ocorreram, também, sob a atuação da frente polar reflexa.

Os resultados poderão servir de base para estudos mais detalhados sobre outros fatores que influenciam o surgimento de nevoeiro no aeródromo da AFA.

\section{REFERÊNCIAS}

.BOIN, M. N. Chuvas e erosões no oeste paulista: uma análise climatológica aplicada. 2000. 264f. Tese (Doutorado em Geociências e Meio Ambiente) - Instituto de Geociências e Ciências Exatas, Universidade Estadual Paulista, Rio Claro, 2000.

.BRASIL. MINISTÉRIO DA DEFESA. DEPARTAMENTO DE CONTROLE DO ESPAÇO AÉREO Portaria DECEA no 77/SDOP, de 16 de outubro de 2008. Aprova a reedição do Folheto sobre os Códigos Meteorológicos METAR e SPECI, 2008.

.DINIZ, J. A. F. Classificação de uma variável e sua aplicação na geografia. Boletim de Geografia Teorética. Rio Claro, n. 1, 1971.

.GERARDI, L. H. de O.; SILVA, B. N. Quantificação em Geografia. São Paulo, SP: Ed. DIFEL, 1981. $163 \mathrm{p}$.

.GULTEPE, I. et al., Fog Research: A Review of Past Achievements and Future Perspectives. Pure appl. geophys. 164, 1121-1159, 2007.

.MCQUITTY, L.L. Similarity Analysis by Reciprocal Pairs for Discrete and Continuous Data. Educational and Psychological Measurement. 26, 825-831, 1966.

.MONTEIRO, C. A. F. Análise rítmica em climatologia: problemas da atualidade climática em São Paulo e achegas para um programa de trabalho. Climatologia. São Paulo, n.1, 21p, 1971.

.NATIONAL OCEANIC AND ATMOSPHERIC ADMINISTRATION (1995). Surface weather observations and reports. Federal Meteorological Handbook. n. 1, 94 p. Disponível em http://marrella.meteor.wisc.edu/aos452/fmh1.pdf. Acessado em: 10/04/2011.

.OLIVEIRA, G. A. Método Estatístico no auxílio à previsão de nevoeiro para o aeródromo de Guarulhos. Dissertação de Mestrado em Engenharia de Produção, Universidade Federal de Santa Catarina, Florianópolis, 2002. 105 p.

.RAMOS, C. da S.; SANCHEZ, M. C. Estudo metodológico de classificação de dados para cartografia temática. Geografia. v. 25, n. 2, p.23-52, 2000.

.SANCHEZ, M. C. A. A problemática dos intervalos de classe na elaboração de cartogramas. Boletim de Geografia Teorética. Rio Claro, n. 4, 1972.

.TAVARES, A. C. Critérios de escolha de anos padrão para análise rítmica. Geografia. Rio Claro, v.1, n.1, p.79-87, 1976.

.ZANDONADI, L. As chuvas na bacia do Paraná: aspectos temporais, espaciais e rítmicos. 2009. (Mestrado em Geografia) - Instituto de Geociências e Ciências Exatas, Universidade Estadual Paulista "Júlio de Mesquita Filho", Rio Claro. 136p. 